EESTI NSV TEADUSTE AKADEEMIA TOIMETISED. XV KÖIDE FUOOSIKA-MATEMAATIKA- JA TEHNIKATEADUSTE SEERIA, 1966, NR. 1

ИЗВЕСТИЯ АКАДЕМИИ НАУК ЭСТОНСКОН̈ ССР. ТОМ ХV СЕРИЯ ФИЗИКО-МАТЕМАТИЧЕСКИХ И ТЕХНИЧЕСКИХ НАУК. 1966, № 1

\title{
ГАЗОХРОМАТОГРАФИЧЕСКИЕ ПОКАЗАТЕЛИ НЕКОТОРЫХ КИСЛОРОДНЫХ СОЕДИНЕНИЙ И ГАЛОГЕНОПРОИЗВОДНЫХ УГЛЕВОДОРОДОВ
}

В настоящем сообщении приводятся некоторые данные о газохроматографических свойствах ряда кетонов, сложных и простых эфиров, спиртов, хлор- и бромпроизводных насыщенных углеводородов на твинах 80 и 20. Определялись три показателя:

1) значения относительных времен удерживания $\left(\tau_{R}\right)$ соединений по отношению к бензолу, время удерживания которого принималось за единицу;

2) индекс удерживания $\left(I_{i}\right)[1]$, рассчитанный с помощью формул

$$
I_{i}=I_{n}+a, a=\frac{\lg \tau_{i}-\lg \tau_{n}}{\lg \tau_{n+1}-\lg \tau_{n}} 100
$$

где $I_{n}$ - индекс парафина с $n$ углеводородными атомами, принятый равным $100 n$,

$\tau_{i}$ - время удерживания исследуемого компонента $i$,

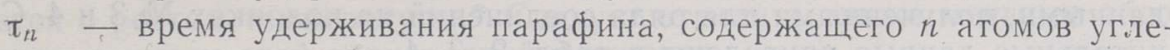
рода,

$\pi_{n+1}$ - время удерживания парафига, содержащего $n+1$ атомов углерода, причем соблюдается условие

$$
\tau_{n}<\tau_{i}<\tau_{n+1}
$$

3) относительная молярная чувствительность $\left(R_{i}\right)$, рассчитанная пю формуле [2]

$$
R_{i}=\frac{\Pi_{i} / x_{i} 100}{\Pi_{6} / x_{6}}
$$

где $\Pi_{i}$ и $\Pi$ - площади пиков исследуемого компонента $(i)$ и бензола (б) на хроматограмме, полученные умножением высоты пика на его шнрину на уровне половины высоты,

$x_{i}$ и $x_{\sigma}$ - молярная концентрация в смеси компонента и бензола соответственно.

Вследствие отсутствия подобных систематических данных в литературе приведенные в настоящей статье данные могут быть использованы

8 ENSV TA Toimetised F-1 66. 
для качественного $\left(\tau_{R}\right.$ и $\left.I_{i}\right)$ и количественного $\left(R_{i}\right)$ определения кислородных соединений и галогенопроизводных жирного ряда.

Газохроматографические показатели определялись при температурах 100,150 и $180^{\circ} \mathrm{C}$. Показатели $\tau_{R}$ и $R_{i}$ рассчитывались на основании хроматограмм смесей компонент - бензол при весовом отношении последних 1: 1, индекс $I$ вычислялся по результатам анализа трехкомпонентных смесей, состоящих из двух парафинов и исследуемого компонента в примерно равных весовых количествах.

Для определения показателей применялись четыре колонки с внутренним диаметром 4 мм. Жидкая фаза составляла 20\% от веса наполнителя. Характеристика колонок приводится в табл. 1.

Таблица 1

Характеристика газохроматографических колонок

\begin{tabular}{|c|c|c|c|c|}
\hline № колонки & Жидкая фаза & $\begin{array}{l}\text { Твердый но- } \\
\text { ситель с ве- } \\
\text { личиной зерен }\end{array}$ & $\begin{array}{l}\text { Длина ко- } \\
\text { лонки, м }\end{array}$ & $\begin{array}{c}\text { Чнсло теорети- } \\
\text { ческих тарелок } \\
\text { по бензолу } \\
\text { при } 100^{\circ}\end{array}$ \\
\hline $\left.\begin{array}{l}1 \\
2 * \\
3 \\
4\end{array}\right\}$ & $\begin{array}{l}\text { Твин } 80 \\
\text { Твин } 20 \\
\text { Твин } 80\end{array}$ & $\begin{array}{l}\text { Хромосорб, } \\
45-60 \text { меш } \\
\text { Силоцель, } \\
60-72 \text { меш }\end{array}$ & $\begin{array}{l}3 \\
6\end{array}$ & $\begin{array}{r}1800 \\
1202 \\
1157 \\
3894\end{array}$ \\
\hline
\end{tabular}

* Меньшая эффективность колонки № 2 объясняется продолжительным использованием ее до проведения настоящей работы.

В качестве газа-носителя применялся гелий со скоростью $50 \mathrm{mл/мuн.}$ На колонке № 1 определялись показатели кетонов, сложных и простых эфиров; на колонке № 2 - показатели спиртов и галогенопроизводных. Данные, полученные с помощью этих колонок, иллюстрируют общие закономерности изменения газохроматографических показателей. Сдєланные на основе этих закономерностей заключения подтверждаются данными, полученными для ряда соединений на колонках № 3 и 4. Сравнительные данные приведены в табл. 2, 3, 4.

Эти таблицы дают возможность проследить следующие закономерности в изменении значений показателей.

Относительные времена удерживания $\left(\tau_{R}\right)$ большинства исследованных соединений уменьшаются с ростом рабочей температуры. Абсолютная величина температурного измерения $\tau_{R}$ увеличивается с ростом температуры кипения соединения (с увеличением абсолютного значения $\tau_{R}$ ). Лишь для некоторых легко кипящих соединений (табл. 2: № 1, 14, $18,19,48-51,57-61) \tau_{R}$ при изменении температуры от 100 до $150^{\circ}$ и от 150 до $180^{\circ}$ либо остается неизменной, либо несколько увеличивается.

Кетоны, сложные эфиры и галогенопроизводные, характеризующиеся близкими значениями температур кипения, имеют близкие значения $\tau_{R}$, значительно превышающие $\tau_{R}$ соответствующих простых эфиров, в то время как относительные времена удерживания соответствующих спиртов превышают значения $\tau_{R}$ всех остальных исследованных соединений. Согласно значениям относительных времен удерживания соединения с близкими температурами кипения можно расположить в следуюпцй ряд: спирты > кетоны, галогенопроизводные, сложные эфиры $>$ простые эфиры.

В рядах соединений одной природы изосоединения характеризуются 
меньшим значением $\tau_{R}$, чем соответствующие нормальные соединения. Кетоны с симметричным строением молекул обладают меньшим значением $\tau_{R}$, чем их несимметричные изомеры, ацетаты характеризуются меньшим значением $\tau_{R}$, чем их изомеры в ряду формиатов (имеющие также более высокую температуру кипения), и, наконец, $\tau_{R}$ хлоропроизводных значительно меньше $\tau_{R}$ соответствующих бромопроизводных.

Значения относительных времен удерживания в рядах кетонов, сложных и простых эфиров с ростом температур кипения соединений растут на твине 20 «быстрее», чем на твине 80 , и тем «быстрее», чем выше рабочая температура. Если $\tau_{R}$ начальных членов рядов на твине 80 превышает $\tau_{R}$ на твине 20, то для более высококипящих членов наблюдается, как правило, обратная закономерность.

Значения относительных времен удерживания спиртов при $100^{\circ}$ на твине 80 меньше, чем на твине 20. При более высоких рабочих температурах с ростом температуры кипения спиртов характер изменения $\tau_{R}$ на твине 80 и твине 20 обратен наблюдаемому в случае кетонов, сложных и простых эфиров.

Относительные времена удерживания галогенопроизводных, определенные на твине 80 при температурах 100 и $150^{\circ}$, выше соответствующих значений $\tau_{R}$ на твине 20 , а для температуры $180^{\circ}$ результат сравнениж соответствующих значений $\tau_{R}$ бромопроизводных аналогичен результату сравнения для кетонов, сложных и простых эфиров.

Значения $\tau_{R}$ спиртов и галогенопроизвсдных на колонке № 4, несмотря на различную длину и другую твердую фазу, практически равны соответствующим значениям, полученным на колонке № 2.

Индекс удерживания $\left(I_{i}\right)$ соединений, указывающий расположение их пиков на хроматограмме между пиками соответствующих парафинов, проявляет, в целом, такую же закономерность изменения, что и значения относительных времен удерживания. Однако в отличие от одинакового характера температурного изменения $\tau_{R}$ у всех исследованных соединений (уменьшение $\tau_{R}$ с ростом рабочей температуры), температурная производная индекса удерживания для всех соединений, кроме спиртов, имеет положительный знак, в то время как значение $I_{i}$ спиртов уменьшается с ростом температуры.* Следует отметить также меньшее абсолютное значение этой производной у спиртов.

Значение относительной молярной чувствительности определялось лишь для оптимальных условий газохроматографического анализа (симметричные пики средней ширины) и для соединений высокой степени чистоты.

В табл. 4 приводятся результаты определения $R_{i}$ при разных температурах на твинах 80 и 20. Для сравнения приводим также некоторые имеющиеся в литературе данные [4,6].

Следует отметить, что данные, приводимые разными авторами, различаются между собой.** Значения $R_{i}$ большинства соединений, полученные в настоящей работе и определенные в разных условиях (при разных температурах и на разных жидких фазах), также заметно отличаются как друг от друга, так и, в большинстве случаев, от данных литературы.

Меньшие колебания в значениях $R$ соединения наблюдаются у спиртов и галогенопроизводных, вместе с тем они и ближе к данным литературы.

* Неподчинение указанному правилу, наблюденное в нескольких случаях, объясняется, на наш взгляд, погрешностью определения $I_{i}$.

** Это справедливо и для $R$ парафинов, которые здесь не приводятся (см. $[3,4])$. 
Таблица 2 .

Относительные времена

удерживания некоторых кислородных соединений и галогенопроизводных

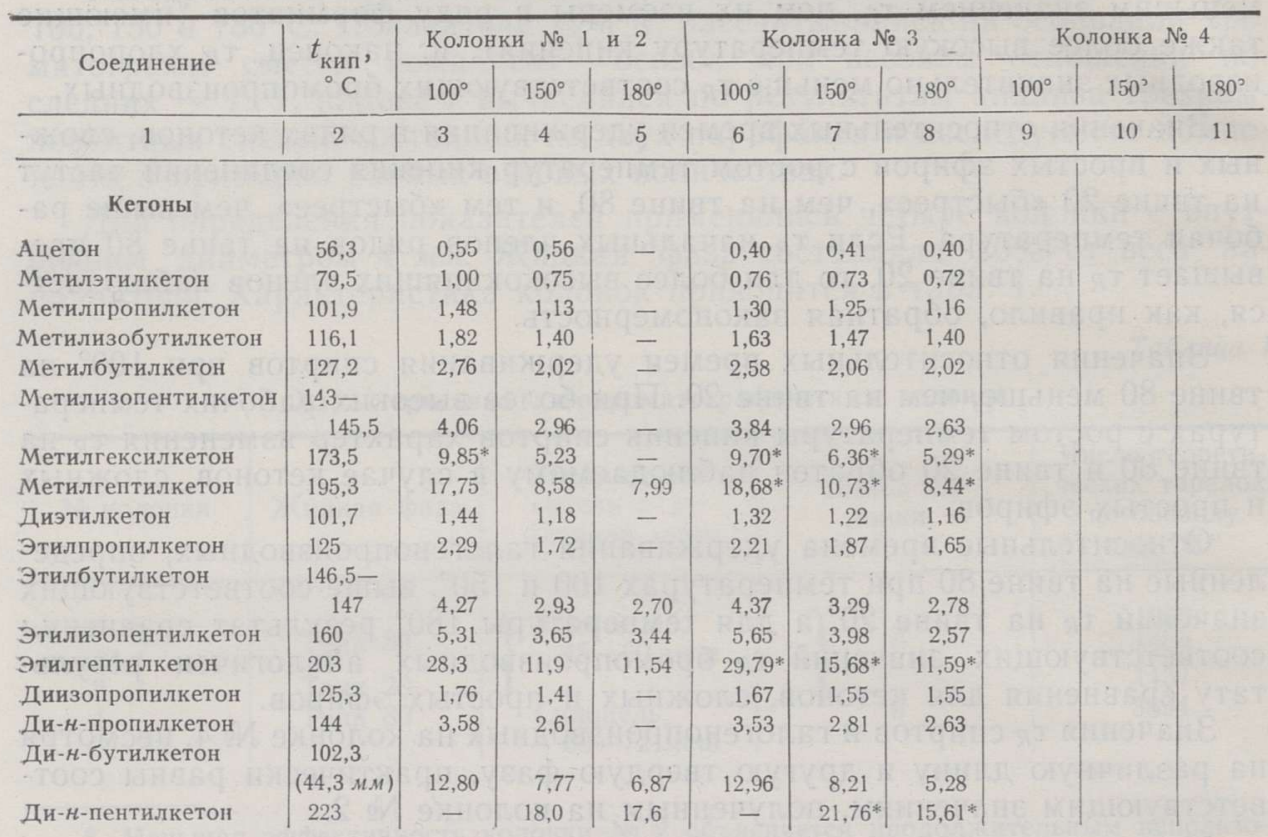

\section{Сложные эфиры}

Метилформиат

Пропилформиат

Бутилформиат

Изоамилформиат

Метилацетат

Этилацетат

Изопропилацетат

Пропилацетат

Изобутилацетат

Бутнлацетат

Изоамилацетат

Амилацетат

Октилацетат

\section{Эфиры}

Диэтиловый

Метилпропиловый

Этилаллиловый

Диизоамиловый

\section{Спирты}

Метиловый

Этиловый

Изопропиловый

Пропиловый

Изобутиловый

Бутиловый

Изоамиловый

Амиловый

Гексиловый

\begin{tabular}{c|r|}
31,9 & 0,29 \\
81,3 & 0,83 \\
106,3 & 1,58 \\
123,3 & 1,86 \\
57,8 & 0,47 \\
77,1 & 0,68 \\
88,6 & 0,76 \\
101,8 & 1,23 \\
118 & 1,56 \\
126,2 & 2,27 \\
142 & 3,22 \\
148 & 4,36 \\
$>171$ & 26,60
\end{tabular}

\begin{tabular}{c|c|c|c|}
- & 0,21 & 0,30 & - \\
- & 0,82 & 0,74 & 0,73 \\
- & 1,62 & 1,49 & 1,33 \\
1,79 & - & 1,99 & 1,69 \\
- & 0,44 & 0,43 & - \\
- & 0,67 & 0,61 & - \\
- & 0,74 & 0,66 & - \\
- & 1,22 & 1,14 & - \\
- & 1,64 & 1,43 & - \\
- & 2,38 & 1,91 & - \\
- & 3,37 & 2,51 & - \\
- & 4,59 & 3,43 & - \\
11,40 & - & 15,75 & -
\end{tabular}

\begin{tabular}{l|l}
34,6 & 0,14 \\
38,9 & 0,17 \\
67,6 & 0,36 \\
$\sim 173$ & 2,74
\end{tabular}


11,95

\begin{tabular}{l|l|l|}
64,7 & 0,52 & 0,45 \\
78,37 & 0,72 & 0,60 \\
82,5 & 0,73 & 0,59 \\
97,25 & 1,50 & 1,22 \\
107,0 & 2,22 & 1,71 \\
117,5 & 3,20 & 2,33 \\
132,05 & 5,14 & 3,52 \\
137,8 & 6,81 & 4,38 \\
157,9 & - & 7,69
\end{tabular}

\begin{tabular}{l|r|}
- & 0,63 \\
- & 0,85 \\
- & 0,84 \\
1,0 & 1,70 \\
1,46 & 2,43 \\
1,63 & 3,48 \\
2,71 & 5,29 \\
3,39 & 6,89 \\
5,72 & 10,12
\end{tabular}

0,56
0,71
0,66
1,28
1,72
2,35
3,46
4,27
7,67

-
0,64
0,56
1,12
1,50
1,98
2,88
3,35
5,65

\begin{tabular}{c|c|c}
0,56 & 0,53 & 0,51 \\
0,75 & 0,68 & 0,60 \\
0,77 & 0,68 & 0,64 \\
1,54 & 1,24 & 1,14 \\
2,26 & 1,75 & 1,51 \\
- & 2,36 & 2,01 \\
- & 3,46 & 2,94 \\
- & 4,39 & 3,52 \\
- & - & 6,19
\end{tabular}

* Определены по o-ксилолу, затем рассчитаны по отношению к бензолу на основе $\mathrm{x}_{R} O$-ксилола. 
Продолжение табл. 2

\begin{tabular}{|c|c|c|c|c|c|c|c|c|c|c|}
\hline 1 & 2 & 3 & 4 & 5 & 6 & 7 & 8 & 9 & 10 & 11 \\
\hline Гептиловый & 176,15 & - & 13,84 & 10,03 & - & 12,82 & 9,80 & 一 & - & 10,24 \\
\hline Нониловый & 213 & - & - & 30,28 & - & 35,51 & 21,74 & 一 & - & - \\
\hline Изодециловый & & & & - & - & - & 36,90 & 一 & - & - \\
\hline
\end{tabular}

\section{Галогенопроизводные}

\begin{tabular}{|c|c|c|c|c|c|c|c|c|c|c|}
\hline Бромэтан & 38,4 & 0,30 & - & 一 & 0,26 & - & - & 0,31 & 0,37 & 0,41 \\
\hline Бромизопропан & 59,35 & 0,41 & - & - & 0,40 & - & - & 0,42 & 0,47 & 0,52 \\
\hline Бромпропан & 70,9 & 0,61 & 0,68 & 0,68 & 0,60 & - & - & 0,61 & 0,66 & 0,70 \\
\hline Бромизобутан & 91,5 & 0,89 & 0,93 & 0,94 & 0,86 & 0,87 & 0,86 & 0,90 & 0,95 & 0,92 \\
\hline Бромизопентан & 120,6 & 1,76 & 1,66 & 1,52 & 1,63 & 1,51 & 1,44 & 1,77 & 1,62 & 1,54 \\
\hline Бромгексан & 156,5 & 4,92 & 3,78 & 3,03 & 4,68 & 3,41 & 3,30 & - & 3,73 & 3,26 \\
\hline Хлоризопропан & 34,9 & 0,20 & - & - & 0,17 & - & - & 0,20 & 0,23 & 0,29 \\
\hline Хлорпропан & 46,6 & 0,29 & - & - & 0.29 & - & $\rightarrow$ & 0,29 & 0,34 & 0,39 \\
\hline Хлоризобутан & 68,9 & 0,42 & - & - & 0,41 & - & - & 0,44 & 0,47 & 0,52 \\
\hline Хлорбутан & 77,9 & 0,58 & 0,62 & 0,61 & 0,57 & 0.57 & - & 0,60 & 0,61 & 0,66 \\
\hline
\end{tabular}

Значения индексов удерживания некоторых кислородных соединений и галогенопроизводных

\begin{tabular}{|c|c|c|c|c|c|c|c|c|c|c|}
\hline \multirow{2}{*}{ Соединение } & \multirow{2}{*}{$t_{\text {кип }}$, } & \multicolumn{3}{|c|}{ Колонки № 1 и 2} & \multicolumn{3}{|c|}{ Колонка № 3} & \multicolumn{3}{|c|}{ Колонка № 4} \\
\hline & & $100^{\circ}$ & $150^{\circ}$ & $180^{\circ}$ & $100^{\circ}$ & $150^{\circ}$ & $180^{\circ}$ & $100^{\circ}$ & $150^{\circ}$ & $180^{\circ}$ \\
\hline 1 & 2 & 3 & 4 & 5 & 6 & 7 & 8 & 9 & 10 & 11 \\
\hline
\end{tabular}

Кетоны

\begin{tabular}{|c|c|c|c|c|}
\hline Ацетон & 56,3 & 772 & 779 & - \\
\hline Метилэтилкетон & 79,5 & 849 & 870 & - \\
\hline Метилпропилкетон & 101,9 & 928 & 947 & - \\
\hline Метилизобутилкетон & 116,1 & 961 & 978 & - \\
\hline Метилбутилкетон & 127,2 & 1028 & 1029 & - \\
\hline Метилизоамилкетон & $143-$ & 1088 & 1089 & - \\
\hline & 145,5 & & & \\
\hline Метилгексилкетон - & 173,5 & 1224 & 1221 & 1252 \\
\hline Метилгептилкетон & 195,3 & - & - & 1351 \\
\hline Диэтилкетон & 101,7 & 924 & 900 & - \\
\hline Этилпропилкетон & 125 & 1000 & 1016 & - \\
\hline Этилбутилкетон & $\begin{array}{r}146,5 \\
-147\end{array}$ & 1100 & 1117 & 1121 \\
\hline Әтилизопентилкетон & 160 & 1141 & 1154 & 1167 \\
\hline Этилгептилкетон & 203 & - & 1462 & 1425 \\
\hline Диизопропилкетон & 125,3 & 969 & 983 & - \\
\hline Ди-н-пропилкетон & 144 & 1079 & 1100 & 1100 \\
\hline Ди-н-бутилкетон & 102,3 & & & \\
\hline & $(44,3 \mu N \mathcal{M})$ & & 1289 & 1300 \\
\hline Ди-н-пентилкетон & 223 & - & 1475 & 1491 \\
\hline Метилформиат & 31,9 & 700 & 一 & - \\
\hline Пропилформиат & 81,3 & 859 & 873 & 一 \\
\hline Бутилформиат & 106,8 & 949 & 968 & - \\
\hline Изоамилформиат & 123,3 & 1020 & 1028 & 1035 \\
\hline Метилацетат & 57,8 & 768 & - & - \\
\hline Этилацетат & 77,1 & 828 & - & - \\
\hline Изопрогилацетат & 88,6 & 843 & 843 & 一 \\
\hline Пропилацетат & 101,8 & 922 & 927 & - \\
\hline Изобутилацетат & $118=$ & 950 & 966 & - \\
\hline
\end{tabular}


Продолжение табл.

\begin{tabular}{|c|c|c|c|c|c|c|c|c|c|c|}
\hline 1 & 2 & 3 & 4 & 5 & 6 & 7 & 8 & 9 & 10 & 11 \\
\hline $\begin{array}{l}\text { Бутилацетат } \\
\text { Изоамилацетат } \\
\text { Амилацетат } \\
\text { Октилацетат }\end{array}$ & $\begin{array}{l}126,2 \\
142 \\
148 \\
>171\end{array}$ & $\begin{array}{r}1014 \\
1065 \\
1110 \\
-\end{array}$ & $\begin{array}{c}1022 \\
1076 \\
1124 \\
-\end{array}$ & $\begin{array}{l}1028 \\
1100 \\
1165 \\
1418\end{array}$ & & & & & & \\
\hline \multicolumn{11}{|l|}{ Әфиры } \\
\hline $\begin{array}{l}\text { Диэтиловый } \\
\text { Метилпропиловый } \\
\text { Этилаллиловый } \\
\text { Диизоамиловый }\end{array}$ & $\begin{array}{r}34,6 \\
38,9 \\
67,6 \\
-173\end{array}$ & $\begin{array}{r}600 \\
619 \\
736 \\
1052\end{array}$ & $\frac{-}{-}$ & $\begin{array}{l}- \\
- \\
1053\end{array}$ & & & & & & \\
\hline \multicolumn{11}{|l|}{ Спирты } \\
\hline Изопропиловый & 82,5 & 810 & 790 & - & 864 & 858 & 841 & 843 & 815 & 799 \\
\hline Пропиловый & 97,25 & 908 & 910 & 897 & 963 & 961 & 885 & - & 917 & 902 \\
\hline Кзобутиловый & 107,0 & 962 & 962 & 958 & 1015 & 1011 & 1009 & - & 974 & 957 \\
\hline Бутиловый & 117,5 & 1014 & 1012 & 1008 & 1069 & 1067 & 1056 & - & 1025 & 1008 \\
\hline Изоамиловый & 132,05 & 1078 & 1076 & 1074 & 1132 & 1133 & 1126 & - & 1090 & 1076 \\
\hline Амиловый & 137,8 & - & 1117 & 1114 & 1173 & 1171 & 1165 & - & 1128 & 1114 \\
\hline Гексиловый & 157,85 & - & 1215 & 1219 & - & 1272 & 1270 & - & - & - \\
\hline Гептиловый & 176,15 & - & 1320 & 1319 & - & 1376 & 1374 & - & - & $\rightarrow$ \\
\hline Октиловый & 195,15 & - & 1424 & 1421 & - & 1478 & - & - & - & 一 \\
\hline
\end{tabular}

Галогенопроизводные

Бромэтан

Бромизопропан

Бромпропан

Бромизобутан

Бромбутан

Бромизопентан

Бромгексан

Бромгептан

Бромоктан

Хлоризопропан

Хлорпропан

Хлоризобутан

Хлорбутан

Хлоризопентан

Хлорпентаң

Хлоргексан

\begin{tabular}{|c|c|c|c|c|c|c|c|c|c|}
38,4 & 699 & - & - & 718 & 751 & 760 & 713 & 710 & 724 \\
59,35 & 738 & - & - & 754 & 784 & 791 & 753 & 750 & 763 \\
70,9 & 788 & 800 & 806 & 807 & 841 & 846 & 808 & 803 & 815 \\
91,5 & 839 & 862 & 894 & 857 & 892 & 876 & 863 & 856 & 863 \\
101,6 & 881 & 911 & 925 & 901 & 930 & 882 & - & 896 & 908 \\
120,6 & 933 & 963 & 979 & 949 & 984 & 1000 & - & 950 & 964 \\
155,5 & 1077 & 1102 & 1116 & 1093 & 1134 & 1140 & - & 1094 & 1115 \\
178,8 & - & 1201 & 1217 & 1191 & 1234 & 1245 & - & - & - \\
$202-$ & - & 1303 & 1316 & - & 1332 & 1343 & - & - & - \\
203 & -1 & & & & & & & & \\
34,9 & 650 & 651 & - & 652 & 708 & - & 650 & 641 & 657 \\
46,6 & 696 & 704 & - & 711 & 751 & - & 705 & 695 & 716 \\
68,9 & 745 & 748 & - & 755 & 780 & - & 761 & 747 & 765 \\
77,9 & 786 & 788 & 818 & 798 & 817 & - & 805 & 795 & 808 \\
98,9 & 842 & 853 & 880 & 854 & 872 & - & 862 & 856 & 865 \\
108,2 & 886 & 901 & 910 & 898 & 910 & - & - & 890 & 908 \\
134,5 & 985 & 998 & 1010 & 995 & 1022 & - & - & 999 & 1008
\end{tabular}

Таблица 4

Относительная молярная чувствительность

\begin{tabular}{|c|c|c|c|c|c|c|c|c|c|c|c|c|c|c|}
\hline \multirow[t]{2}{*}{ Соединение } & \multicolumn{3}{|c|}{ Колонка № 1} & \multicolumn{2}{|c|}{ Колонка } & № 2 & \multicolumn{3}{|c|}{ Калонка № 3} & \multicolumn{3}{|c|}{ Колонка № 4} & \multicolumn{2}{|c|}{$\begin{array}{c}\text { Данные } \\
\text { литера- } \\
\text { туры }\end{array}$} \\
\hline & $100^{\circ}$ & $150^{\circ}$ & $180^{\circ}$ & $100^{\circ} \mid$ & $150^{\circ}$ & $180^{\circ}$ & $100^{\circ}$ & $150^{\circ}$ & $180^{\circ}$ & $100^{\circ}$ & $150^{\circ}$ & $180^{\circ}$ & {$[4]$} & {$\left[{ }^{6}\right]$} \\
\hline 1 & 2 & 3 & 4 & 5 & 6 & 7 & 8 & 9 & 10 & 11 & 12 & 13 & 14 & 15 \\
\hline \multicolumn{15}{|l|}{ Кетоны } \\
\hline Ацетон & 81,5 & - & - & & & & 73 & 75 & - & & & & $86^{* *}$ & 65 \\
\hline Метилэтилкетон & - & 80 & 一 & & & & 89 & 93 & - & & & & 98 & 80 \\
\hline $\begin{array}{l}\text { Метилпропилке- } \\
\text { тон }\end{array}$ & 116 & 124 & - & & & & 115 & 112 & 112 & & & & & 97 \\
\hline
\end{tabular}


Продолюение табл. 4

\begin{tabular}{|c|c|c|c|c|c|c|c|c|c|c|c|c|c|c|}
\hline 1 & 2 & 3 & 4 & 5 & 6 & 7 & 8 & 9 & 10 & 11 & 12 & 13 & 14 & 15 \\
\hline $\begin{array}{l}\text { Метилизоамил- } \\
\text { кетон }\end{array}$ & 136 & 153 & - & & & & 127 & 126 & - & & & & & \\
\hline $\begin{array}{l}\text { Метилгексил- } \\
\text { кетон }\end{array}$ & $175^{*}$ & $186^{*}$ & - & & & & $164 \star$ & $177^{\star}$ & $158^{\star}$ & & & & 147 & 161 \\
\hline $\begin{array}{l}\text { Метилгептил- } \\
\text { кетон }\end{array}$ & 200 & $203^{*}$ & - & & & & $173^{\star}$ & $177^{\star}$ & $177^{\star}$ & & & & & 182 \\
\hline Диэтилкетон & 111 & 116 & - & & & & 103 & 102 & - & & & & 110 & 98 \\
\hline Этилпропилкетон & 131 & 148 & - & & & & 107 & 122 & - & & & & & \\
\hline Этилбутилкетон & 134 & 173 & 一 & & & & 134 & 151 & 156 & & & & & \\
\hline $\begin{array}{l}\text { Этилизопентил- } \\
\text { кетон }\end{array}$ & 143 & 189 & - & & & & 156 & 169 & 148 & & & & & \\
\hline Этилгептилкетон & 247 & $201^{*}$ & - & & & & $193^{\star}$ & $194^{\star}$ & $168^{\star}$ & & & & & \\
\hline Диизопропилкетон & 128 & 121 & - & & & & 125 & 138 & 143 & & & & & \\
\hline Ди-н-пропилкетон & 130 & 142 & 一 & & & & 133 & 120 & 140 & & & & & \\
\hline Ди-н-бутилкетон & 146 & 176 & - & & & & 148 & 149 & 145 & & & & & \\
\hline Ди-н-пентилкетон & - & $211^{*}$ & - & & & & - & $185^{*}$ & $188 *$ & & & & & \\
\hline
\end{tabular}

\section{Сложные эфиры}

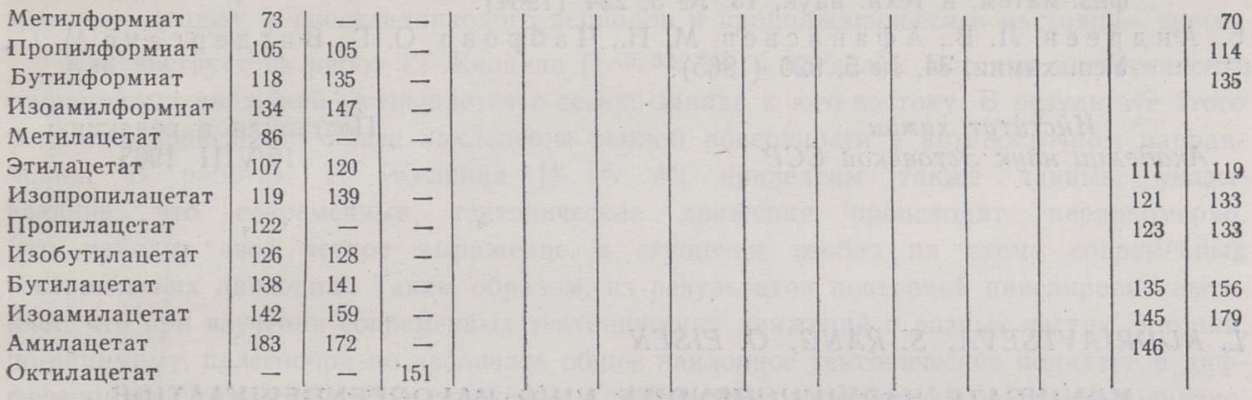

\section{Эфиры}

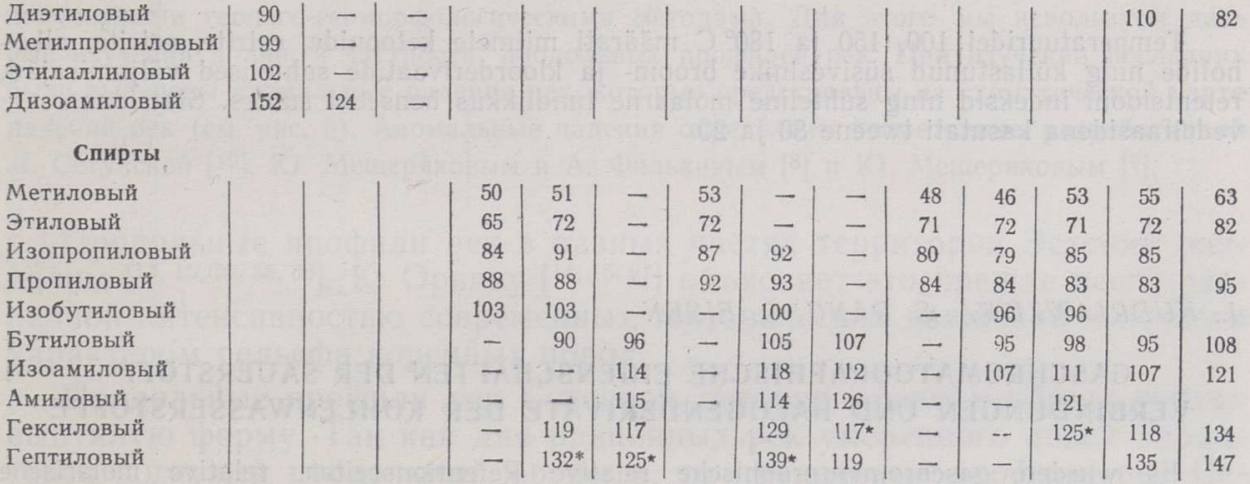

Галогено-

производные

Бромэтан

Бромизопропан

Бромпроган

Бромизобутан

Бромбутан

Бромизопентан

Бромгексан

Бромгептан

Брамоктан

\begin{tabular}{r|r|r|r|r|r|r|r|r}
80 & - & - & 73 & - & - & 85 & 82 & 68 \\
103 & - & - & 98 & - & - & 94 & 89 & 90 \\
92 & 92 & - & 91 & - & - & 91 & 91 & 90 \\
103 & 108 & - & 108 & - & - & 111 & 110 & 111 \\
110 & 115 & 113 & 114 & - & - & 116 & 114 & 112 \\
135 & 135 & - & 126 & 124 & 127 & 144 & 143 & 149 \\
132 & 141 & - & - & 124 & 130 & - & 131 & 120 \\
- & 168 & - & - & - & - & - & - & - \\
- & 171 & - & - & - & - & - & - & -
\end{tabular}

* Рассчитано по результатам анализа смеси компонент-о-ксилол и пересчитано по отношению к бензолу с учетом 0 -ксилола по бензолу.

** Согласно $\left.{ }^{3}\right]-72$. 
При исследовании возможности разделения углеводородов на твинах мы уже отмечали универсальный характер этих жидких фаз [5]. Данные настоящей работы свидетельствуют о возможности их применения и для анализа кислородных соединений и галогенопроизводных. Отсюда следует, что твины как жидкие фазы могут быть использованы для газохроматографического анализа сложных смесей, состоящих из компонентов различной природы, например, азеотропных смесей.

\section{Л И Т Е Р А Т Р А}

1. Ettre L. S., Anal. Chem., 36, No. 8, 31A (1964).

2. Messner A. E., Rosi e D. M., Argabright P. A., Anal. Chem., 31, No. 2, 230 (1959).

3. S chomburg G., Z. Analyt. Chem., 164, No. 1, 147 (1958).

4. Rosie D. M., Grob R. L., Analyt. Chem., 29, No. 9, 1263 (1957).

5. Эйз ен Ю., Кудрявцева Л., Р анг С., Эйзен О,, Изв. АН ЭССР. Сер. физ.-матем. и техн. наук, 13, № 3, 234 (1964).

6. Андреев Л. В., Афан асьев М. И., Ч а бров а О. Г., В игдергаус М. С., Усп. химии, 34, № 5, 920 (1965).

Ннститут химии

Академии наук Эстонской ССР

Поступила в редакцию 19/VIII 1965

L. KUDRJAVTSEVA, S. RANG, O. EISEN

\section{MÕNINGATE HAPNIKUÜHENDITE NING HALOGEENDERIVAATIDE GAASIKROMATOGRAAFILISED NÄITAJAD}

Temperatuuridel 100,150 ja $180^{\circ} \mathrm{C}$ määrati mitmete ketoonide, estrite, eetrite, alkoholide ning küllastunud süsivesinike broom- ja kloorderivaatide suhtelised väljumisajad, retentsiooni indeksid ning suhteline molaarne tundlikkus benseeni suhtes. Statsionaarsete: vedelfaasidena kasutati tweene 80 ja 20 .

L. KUDRJAWZEWA, S. RANG, O. EISEN

\section{GASCHROMATOGRAPHISCHE EIGENSCHAFTEN DER SAUERSTOFF- VERBINDUNGEN UND HALOGENDERIVATE DER KOHLENWASSERSTOFFE}

Es wurden gaschromatographische relative Retentionszeiten, relative molarische: Empfindlichkeit und Retentionsindexe von Sauerstoffverbindungen und Halogenderivaten der Kohlenwasserstoffe bestimmt. Als flüssige Phase dienten Tween 80 und Tween 20. 